\title{
Capacity building at community forestry level for synergistic implementation of NDCs' adaptation and mitigation commitments
}

\author{
Binaya Raj Shivakoti $^{\mathrm{a}}{ }^{*}$, Federico Lopez-Casero $^{\mathrm{a}}$, Tek Maraseni $^{\mathrm{b}}$, Krishna Pokharel $^{\mathrm{c}}$ \\ ${ }^{a}$ Institute for Global Environmental Strategies (IGES), Kanagawa, Hayama, Japan \\ ${ }^{\mathrm{b}}$ Centre for Sustainable Agricultural Systems, University of Southern Queensland, Queensland, Australia \\ ${ }^{\mathrm{c}}$ Koteshwor, Kathmandu, Nepal \\ *Corresponding author.Email: shivakoti@iges.or.jp.
}

\section{ABSTRACT}

Conservation, restoration and management of forest resources are critical for addressing climate change. Nationally Determined Contributions (NDCs) are a vehicle for targeted climate actions, including those related to forest management, by countries towards contributing global efforts agreed under the Paris Agreement. Operationalizing climate action stipulated in NDCs requires adequate preparedness and capacity, especially at the local level. This paper suggests a comprehensive framework of capacity building targeting at the community forestry level based on the findings of capacity needs assessments carried out in Nepal. The framework outlines a method to develop capacity among forest communities so they can carry out integrated assessments of the outcomes related to sustainable forest management, mitigation, adaptation and the quality of governance. Further, it outlines the capacity needed for integrated planning and implementation to consolidate the assessment process and make progress in an adaptive manner. By filling the capacity gaps at the community forestry level in a comprehensive manner, countries can narrow the existing divide between local-level climate actions and upper-level (national and international level) policy priorities, which is the major barrier for translating climate commitments into action.

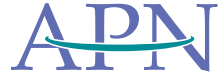




\section{HIGHLIGHTS}

- There is a communication gap between local and national/international levels, which hampers the effective implementation of prioritized forest-related climate actions in NDCs.

- Capacity building at the community forestry level is critical for connecting priorities set out in the NDCs with effective actions on the ground by facilitating an exchange of information and support (technical, financial), and recognition of local contributions in a transparent manner.

- Given the shortcomings of stand-alone capacity building initiatives, we recommend a comprehensive approach to capacity building under a framework of sustainable forest management for synergistic outcomes as well as to safeguard the interests and rights of the forest communities.

- Ultimately, each forest community should be able to plan, decide and lead climate actions that streamline NDCs priorities while contributing to their resilience building. A comprehensive approach, therefore, is critical for long-term capacity building at the local level.

\section{INTRODUCTION}

Climate change affects forests significantly and forests influence climate change at different scales and in complex ways. Improved management and better governance of forest resources are critical for achieving global warming targets $\left(1.5^{\circ} \mathrm{C}\right.$ or $\left.2^{\circ} \mathrm{C}\right)$ as well as to accelerate the global adaptation goal of the Paris Agreement (UNFCCC, 2015). The forestry sector is among the few sectors promising dividends for mitigation and adaptation simultaneously. The ability of forest ecosystems to sequester carbon and to provide multiple ecosystem services is a simple yet cost-effective nature-based solution for largescale climate action (IPCC, 2019; Austin et al., 2020; Girardin et al., 2021).

Forests are simultaneously a source (i.e. problem) and a sink (i.e. solution) for greenhouse gas (GHG) emissions as global forests contain vast carbon stock (i.e. including all carbon pools) of an estimated 662 gigatonnes $\mathrm{CO}_{2}$ equivalent $\left(\mathrm{GtCO}_{2} \mathrm{e}\right)$ (163 tonnes $\mathrm{CO}_{2}$ e per ha) in soil organic matter, liv- ing biomass, and dead wood and litter (FAO, 2020a). With current $15 \%$ of GHG emissions coming from forests, potential release of GHG from forest stock can pose a serious barrier for realizing the Paris Agreement if we consider the remaining cumulative budget of less than $600 \mathrm{GtCO}_{2} \mathrm{e}\left(1.5^{\circ} \mathrm{C}\right.$ by 2100 scenario from 2018) or the rate of the total annual global emissions (53.5 $\mathrm{GtCO}_{2} \mathrm{e}$ in 2017) (UNEP, 2018; FCPF, 2020). Land-based mitigation and land-use change is required for limiting warming to $1.5^{\circ} \mathrm{C}$, or well below $2^{\circ} \mathrm{C}$, by adopting different combinations of reforestation, afforestation, reduced deforestation and bioenergy (IPCC, 2019).

Forests are susceptible to climate changeinduced risks such as forest fires, loss of productivity due to inadequate rainfall and excess heat, erosion/damage of the forested area from climate-induced hazards (landslides, floods, etc.). Climate change could adversely affect different dimensions of forests, including occurrences, distribution and diversity of tree 
species, harvest levels, and quality/quantity of ecosystem services (IPCC, 2019).

Forest conservation, restoration and management, therefore, are not only useful for mitigation, but are also equally crucial for adaptation. Forests, as a socio-ecological system (SES), offer a range of ecosystem services (provisioning, regulating, habitat support and cultural services). Interventions such as watershed conservation, preserving and restoring natural forest ecosystems, agroforestry, fire management, soil management, disaster risk management or ecosystem-based adaptation options have the potential to make positive contributions to sustainable development and enhancement of ecosystem functions and services (IPCC, 2019).

\subsection{Scope of forest resources in the Paris}

\section{Agreement and NDCs}

Although major discussions and responses on climate change are skewed towards the mitigation potential of forests, the essence of Article 5.2 of the Paris Agreement is that climate change adaptation and other ecological functions of forests should proceed in an integrated manner with mitigation goals (UNFCCC, 2015). Climate change actions targeting forest resources, such as Reducing Emissions from Deforestation and Forest Degradation, and the Role of Conservation, Sustainable Management of Forests and Enhancement of Forest Carbon Stocks in Developing Countries (REDD+), cannot be stand-alone initiatives but should contribute and complement mitigation, conservation, livelihood support, and building resilience while minimizing risks and vulnerability. Major declarations such as the Paris Agreement, New York Declaration on Forests (NYDF), Global Forest Goals (GFGs) and Targets under the UN Strategic Plan for Forests 2030, Sustainable Development Goals (SDGs), and Aichi Biodiversity Targets have well-acknowledged this viewpoint (CBD, 2010; UN, 2015; UNFCCC, 2015; UN, 2017; IUCN \& ForestAction, 2020; UN, 2014).

Article 5.2 of the Paris Agreement stipulates the importance of forest-related climate action. The article asks Parties to take action to conserve and enhance, as appropriate, sinks and reservoirs of GHG such as through REDD+. Further, the PA also gives a clear signal by stressing joint mitigation and adaptation approaches for the integral and sustainable management of forests.

Nationally Determined Contributions (NDCs) is another important feature of the Paris Agreement. Countries are to undertake and communicate ambitious NDCs as the global response to climate change for achieving the purpose of the agreement. NDCs adopt a bottom-up process that allows countries to submit their commitments. It is a pragmatic solution for setting realistic ambitions and ensuring effective implementation, as countries are free to decide on the content, process and timeline of intended climate action that they will take. NDCs will guide climate action and thus constitute the main vehicle for implementing, tracking and communicating progress made by each country.

The commitments expressed in many NDCs by individual countries have prominently featured forest or forest ecosystems (IUCN \& ForestAction, 2020). The submitted NDCs recognize mitigation and adaptation contributions of the forest sector mostly emphasizing coordinated responses. In 165 NDCs examined, forest sector-related targets on mitigation and adaptation were submitted by 156 and 93 countries, respectively (IUCN \& ForestAction, 2020). For instance, Indonesia's NDCs view mitigation and adaptation as an integrated concept, such as by reducing deforestation and forest degradation, ecosystem conservation/restoration or integrated watershed management, for achieving food, water, energy security and building resilience (GoI, 2016). Nepal's NDCs emphasize developing "mitigation-friendly forest management systems" and enhancing carbon sequestration through sustainable management of forests, programmes reducing emissions from forest areas, as well as adaptationfriendly community-based forest and climateresilient watershed management (GoN/MoPE, 2016). The NDCs highlight building climateresilient watersheds, making community-based 
forests climate adaptation-friendly, and designing and implementing community adaptation plans of action (CAPAs) based on forest and non-forest benefits.

\subsection{Addressing capacity gaps for translating NDCs' commitments into actions on the ground}

Despite significant improvements in policy, such as establishing mechanisms for REDD+, concrete measures to integrate climate action on the ground are yet to gain traction in the absence of meaningful participation of the concerned stakeholders such as community forestry (Cadman, Maraseni, Ma, \& Lopez-Casero, 2017). Participation does not imply inviting stakeholders or filling quorum for consultations (Bastakoti \& Davidsen, 2016; Cadman et al., 2017). Rather, it interweaves deeper into capacity barriers at the community level such as fully understanding the roles, responsibilities, costs and benefits involved in participation, and the ability to make informed decisions to safeguard core interest and resource sustainability (Maraseni et al., 2020). Inadequate readiness at the community level hampers the whole prospect of implementing NDCs through sustainable forest management.

The existing gap between policy and action has resulted in resources being concentrated in the upper echelons of the policy community and largely unavailable at the local level, where capacity building is needed the most (Cadman et al., 2017). For instance, gaps between international requirements for monitoring climate actions (such as MRV of REDD+) and the existing forest monitoring systems (such as the community level) can seriously hamper the implementation of planned climate action at the community level (Dhungana, Poudel, \& Bhandari, 2018). Governments need to pay adequate attention by allocating proper resources to fill capacity gaps and thus, ensure meaningful participation at the local level, such as Community Forest User Groups (CFUGs), to implement NDCs and mainstream their efforts into the broader national and international processes. For that, it is crucial to fully understand the key capacity gaps and enable CFUGs to make informed decisions.

This paper proposes a comprehensive framework for capacity building in community forestry, such as CFUGs, targeting the effective implementation of NDC's adaptation and mitigation commitments. It builds largely on the observations and findings from a capacity building needs assessment (CBNA) at multi-levels conducted in five provinces of Nepal in 2019 and 2020. We expect that the recommendations will be useful for designing capacity building activities at the community forestry level to implement relevant NDC commitments not only in Nepal but also other counties.

\section{METHODOLOGY}

We adopted action research - in this case, capacity building of communities while identifying capacity needs - in four out of the seven provinces in Nepal. The methodological approach is shown in the Figure 1.

We conducted a series of multi-stakeholder CBNA workshops (at least one per province) consisting of lectures, focussed group discussions, trial assessment of quality of governance, group exercises and exposure visits to select community forestry sites (Lopez-Casero, Shivakoti, Maraseni, Pokharel, \& APN, 2021). Each workshop had at least 25 participants. The stakeholders were made up of a diverse set of actors from all levels of government (federal, provincial, district and community) representing the environment, climate change, forestry, agriculture and local development, as well as from national and international organizations dealing in forest management, climate change, CFUGs, the Federation of Community Forestry Users Nepal (FECOFUN), etc. Lectures in each CBNA workshop covered familiarization of NDCs, measures for the integration of climate change action into the CFUGs, and monitoring and assessment of the performance of CFUGs. The lectures were delivered by national and international experts, including government officials. The focus group discussions were conducted with government officials (at district and provincial levels) and the community level 


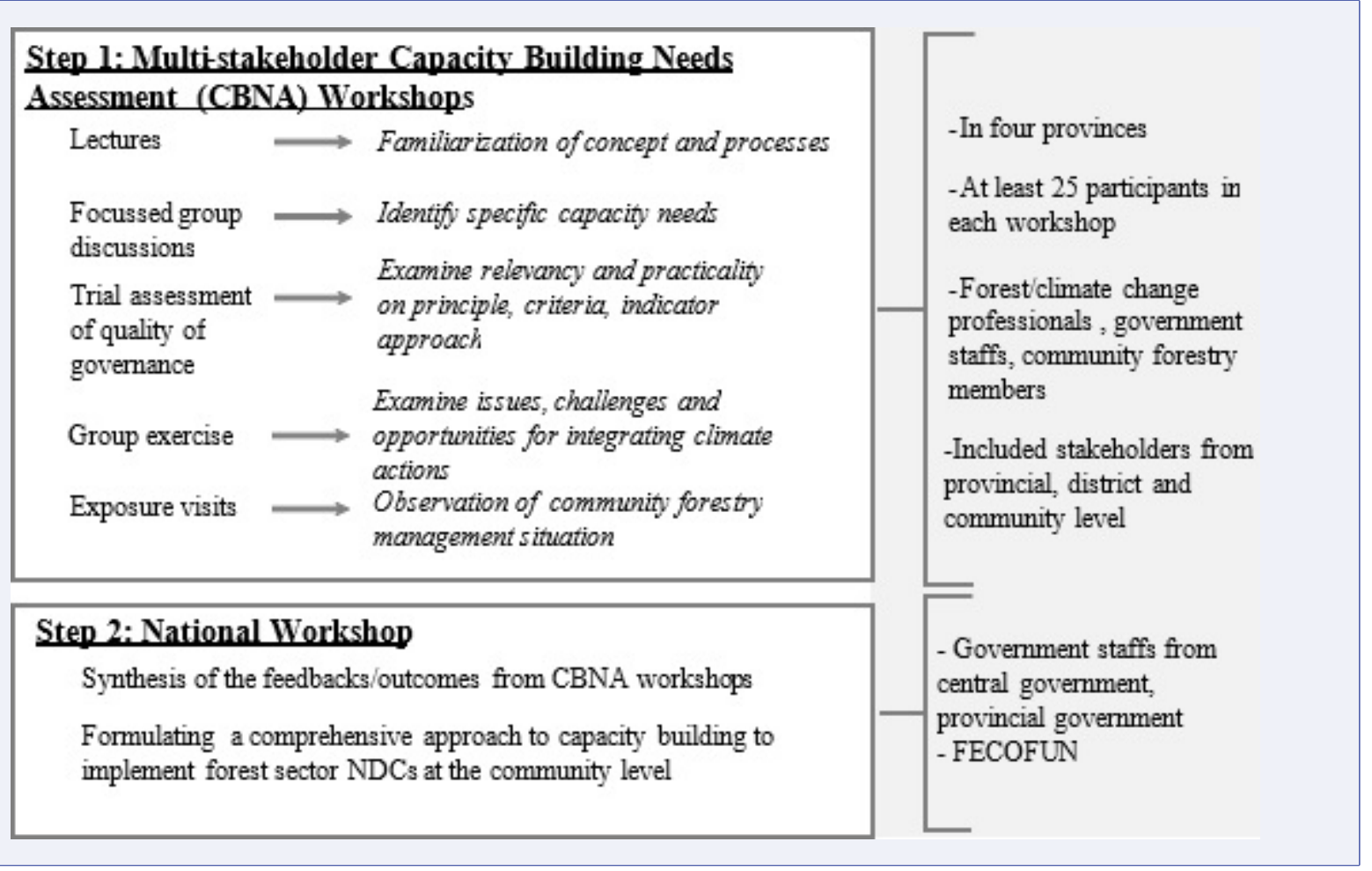

FIGURE 1. Methodological framework to identify capacity needs.

(members of CFUGs, FECOFUN) to identify capacity building needs. After the focus group discussions, trial assessment of the quality of governance (Lopez-Casero, Cadman, \& Maraseni, 2016) was conducted to examine the relevancy and practicality of applying the principle, criteria and indicator framework to assess the governance, including indicators related to climate action. Further, group exercises were employed to identify challenges, needs and opportunities, such as needed resources, tools and equipment, hands-on exposure and institutional coordination required for implementing NDC commitments at the CFUG level. Exposure visits helped to further clarify the issues and challenges of forest management identified during the discussion sessions. Towards the end of the CBNA, key lessons and outcomes were shared with all participants that included identification of common concerns and expectations with regards to the modality of forest management and monitoring activities, gaps in technical and management capacity such as for monitoring carbon, how to adapt to climate change impacts and emerging concerns such as forest fires, drought, conflict with wildlife (such as monkeys), concerns on the impact of climate action such as REDD+ on the use of forest resources, social issues (migration of youth force), mainstreaming local action into national and international processes, etc. We examined the key outcomes of all CBNA workshops at the national workshop to identify a comprehensive approach to capacity building, which is also the main highlight of this paper.

\section{RESULTS AND DISCUSSION}

\subsection{Capacity Building Needs Assessment (CBNA) at community forestry level}

Community-based forest management (CBFM) is a participatory approach to managing forests under the autonomy vested to forest users (i.e. stewards) as opposed to centralized control of forest management by the government. It includes formalized customary and indigenous processes as well as government-led initiatives covering social, economic and conservation dimensions in a range of activities (FAO, 2016). Communities can play a significant role in sustainable forest management when they are empowered to participate in decision-making and equitable benefit sharing (RECOFTC, 2013). In the past four 
decades, CBFM regimes encompassed an estimated 732 million hectares, which is about $28 \%$ of the forests in the 62 countries or $65 \%$ of the world's forests cover (FAO, 2016). Effectiveness of CBFM is evident by its increasing coverage throughout the Asia-Pacific region such as Nepal, Viet Nam, Myanmar, China, the Philippines and many other countries (Feurer, Gritten, \& Than, 2018; RECOFTC, 2013).

Nepal is considered a pioneer for successfully implementing CBFM (MOFE, 2019). Local communities under different CBFM regimes (e.g., community, collaborative or leasehold forestry) plan and manage over one-third of the forest area (MOFE, 2018). The Forest Act provides clarity on the tenure rights of the community forestry regime. As a result, CBFM has been quite successful in its core objectives for resource conservation and maintaining a supply of fodder, timber and fuelwood along with the flow of environmental and cultural services (Aryal, Laudari, \& Ojha, 2020). However, as identified in the workshops, the reliance of community forestry on traditional or indigenous management practices has been unable to tap the full potential of forests to meet current needs, including climate change actions. This means that it can be challenging to ensure the full involvement of CFUGs in marketbased mechanisms, such as REDD+, due to the lack of capacity in understanding the technicalities of opportunities and risks from climate change or concerns over safeguarding existing rights of CFUGs (Dhungana et al., 2018).

The integration of climate change into CFUGs governance regime is indispensable to address risks, tap into opportunities and build resilience. Forest management needs a more active and outcome-oriented approach to address livelihood expectations, contribute climate change solutions and ensure sustainability.

One basic question at the CUFGs level in Nepal is the state of preparedness to undertake reforms for contributing to NDCs commitments. The CBNA found a significant gap in understanding about the nature of involvement and incentives for inte- grating climate change action into the community forestry regime (Figure 2).

First, there was a need for communicating the NDCs commitments and relevant government policy and actions to CFUGs at regular intervals. CFUGs are unable to assess risks and opportunities resulting from major policy developments at the national and international levels as such information rarely reaches them. It is often hard for them to assess their role and responsibilities or incentives (benefits, support, recognition of efforts) to implement NDCs.

The second gap is on the process and scope of implementation. Targeted programmes on climate change, such as REDD+, tend to stress the carbon benefits more than other issues such as social and environmental safeguards, adaptation co-benefits and other livelihood concerns, which in principle are fully integrated into REDD+ design.

The third gap relates to monitoring and assessment. Programmes related to REDD+ involve a rigorous process of monitoring, reporting and verification (MRV) of sinks and emissions, which require extra resources and effort by communities to secure performance-based payment. In addition to carbon benefits, communities need to monitor and assess climate change impacts on forests, adaptation outcomes, the quality of governance and other non-carbon indicators related to sustainable forest management. Without adequate capacity and incentives, these requirements would simply add layers of burden to the existing forest management tasks.

The fourth gap is in the planning and implementation of climate action. This requires building technical, financial, infrastructure, human resources and institutional capacities to administer climate action transparently. Communities need to upgrade their capacity to facilitate coordination, communication and negotiation with external parties (both private and public sources offering support in the form of finance, technology, or skills). CBNA workshops identify that incorporating climate change components (mitigation and 


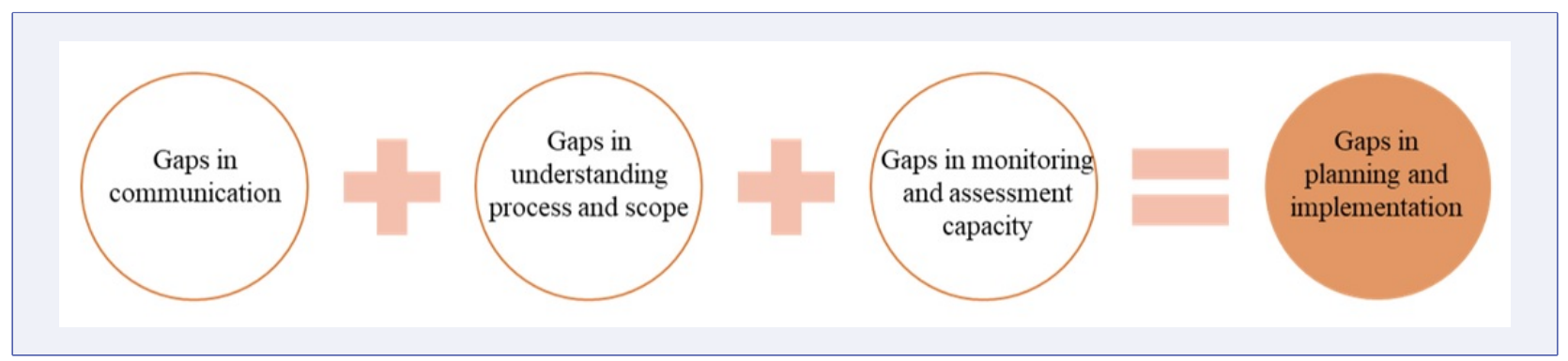

FIGURE 2. Four major capacity gaps at the community forestry user group (CUFG) for implementation of NDCs commitments targeting the forest sector.

adaptation) into forest management needs careful consideration of issues on equitable benefit sharing and additional incentives for motivating CFUGs participation.

In addition to the capacities mentioned above, the participants in CBNA workshops also identified additional issues faced by CFUGs such as rising socio-economic expectations under modern lifestyles, migration, market forces (timber and non-timber products) and land-use dynamics. These non-climatic issues reflect the concern that the design and implementation of climate change-related actions need a synergistic approach to ensure the overall sustainability of SES.

\subsubsection{Comprehensive framework for capacity building at the community forestry level}

In order to address the identified capacity gaps, a much broader objective for ensuring sustainable forest management (SFM) as well as addressing climate change concerns is needed. SFM is a dynamic concept that aims to maintain and enhance the economic, social and environmental values of all types of forests, for the benefit of present and future generations (FAO, 2020b). SFM involves the application of the best available practices based on current scientific and traditional knowledge, including effective and accountable governance, that allows multiple objectives and needs to be met without degrading the forest resource and while safeguarding the rights of forest-dependent peoples (ITTO, 2015).

SFM could be the overarching concept for community forestry to follow for the effective implementation of NDCs commitments while achieving a resilient SES. Elements of SFM are comprehensive and cover state (resources, biodiversity, health and vitality), functions (production, protection and socio-economic) and enabling conditions for management (legal, policy and institutional framework) (FAO, 2020b). The broad scope of SFM signifies that it must be flexible and constantly adaptive to stay relevant and useful according to stakeholders needs, values, resources, institutions and technologies (ITTO, 2015). Because of the dynamic, multidimensional, multipurpose and multiuse framing of SFM, major assessment reports (i.e. IPCC, IPBES) or agreements/decisions (Paris Agreement, SDG15, the NYDF, GFG, Aichi Targets, etc.) frequently stress the need for its adoption and application. SFM can reduce the extent of forest conversion to non-forest uses (e.g. cropland or settlements) by providing long-term livelihoods for communities, while ensuring timber, fibre, biomass, nontimber resources and other ecosystem functions and services, lowering GHG emissions and contributing to adaptation (IPCC, 2019). SFM is one of the key pillars of REDD+ action that can help integrate and optimise carbon and non-carbon benefits. For instance, SFM allows transferring carbon to wood products, which addresses the issue of mitigation from biomass for energy (where burning releases $\mathrm{CO}_{2}$ back into the atmosphere) and sink saturation in mature forest stands (IPCC, 2019).

Given this background and identified capacity gaps, we propose a comprehensive framework for capacity building that would enable achievement of NDCs commitment through SFM, as shown in Figure 3. 


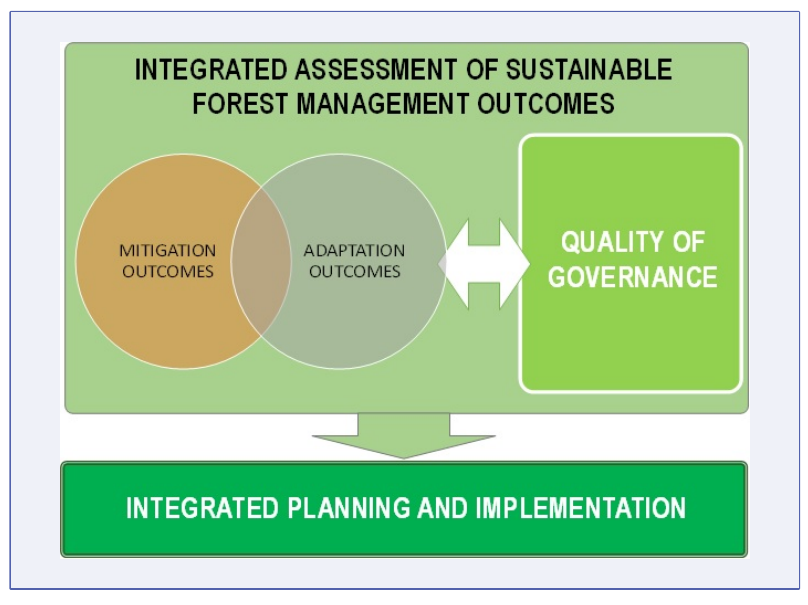

FIGURE 3. A framework for capacity building at the community forestry level for implementation of NDCs commitments through sustainable forest management.

The proposed framework consists of two parts: assessment of SFM outcomes and integrated planning and implementation. Assessment mainly covers outcomes resulting from SFM incorporating mitigation, adaptation and quality of governance. Here, the assessment of the quality of governance helps to cement the integrity of actions by ensuring transparency, participation and institutional coordination. The integrated planning and implementation (IP\&I) part addresses the capacity gaps by putting in place appropriate arrangements to implement climate and non-climate action in an adaptive manner. IP\&I consolidates overlapping indicators for an integrated assessment, and it can help to determine the level of coordination. IP\&I can also identify resources and capacity (both available and what's needed) from external sources, and encourage adaptive planning and implementation based on the evaluation of key performance indicators.

\subsection{Capacity building for the integrated assessment of SFM outcomes}

Assessment is critical for examining progress on NDCs implementation, identifying challenges, and for prioritizing actions. It can be the basis to enhance ambitions or to justify requests for external support. Communities can use scientifically verifiable data generated from the assessment to identify effective forest management options and report contributions to government including requests for support or result-based payments (such as REDD+). During CBNA, the involvement of communities in the assessment was found as a critical capacity gap towards improving decision-making, both internally and when dealing with outsiders.

\subsubsection{Assessment of SFM outcomes}

The assessment of SFM is broad and also incorporates mitigation, adaptation and quality of governance. SFM could be a basis and starting point for designing community-level monitoring and assessment of outcomes. The assessment of SFM is generally achieved using a hierarchical approach of principle, criteria and indicators (PC\&I), which is a powerful framework to define, characterize, guide, monitor and assess progress towards SFM in a given context (ITTO, 2016). Principles are statements of goals or values that provide a crucial foundation for SFM. They form the basis for defining criteria and specific indicators for monitoring. Since the first set of PC\&I developed by the International Tropical Timber Organization (ITTO) in 1992, it has gone through different modifications (MartnGarca \& Diez, 2012). CFUGs must design their PC\&I by considering local circumstances (including resource availability and capacity), SFM objectives, applicable laws, practices and guidelines.

\subsubsection{Assessment of mitigation outcomes}

Although SFM encapsulates mitigation contributions in many ways, assessing mitigation outcomes can be complex and thus requires familiarization of additional steps. For instance, mitigation contributions, such as from REDD+, should undergo MRV that complies with an international standard to be eligible for results-based payment (UNFCCC, 2014). MRV is essential for the recognition and visibility of action undertaken by CFUGs.

Capacity gaps remain for actual implementation since mitigation activities will mainly take place at the community forestry level. One of the suggestions in the workshops was to empower CFUGs to conduct community-level carbon accounting while the responsible government agencies conduct additional tasks that are not 
effective/pragmatic at the community level (such as processing of satellite data) at least in the early stages. Community-based forest biomass monitoring (CBFBM) can be employed as it relies on a participatory approach that enables the community to drive and own the monitoring process with or without external guidance and facilitation (Edwards, Scheyvens, Stephenson, \& Fujisaki, 2014). CBFBM aims to build the capacity of communities to conduct monitoring in a reliable manner using scientifically proven methods and tools, which typically are left in the hands of forest professionals. A combination of scientific and local/traditional methods is the real advantage of CBFBM as it ensures that the whole monitoring process is compatible with the local specificities and available resources.

\subsubsection{Assessment of adaptation outcomes}

A major and evolving concern are the impacts of climate change on forests that could have farreaching impacts on the sustainability of forest ecosystems. Forests can be affected by a variety of climate change-induced natural causes and anthropogenic actions such as encroachment, illegal harvesting, wildfire, animal grazing, mining and construction, the spread of invasive species, pests and diseases, impacts of extreme weather events (e.g. heavy rainfall, flooding and drought), etc. Communities need local approaches to monitor vulnerability and threats on forests and on dependent livelihoods enabling them to plan adaptation measures to enhance the resilience of forest ecosystems and dependent communities.

For the implementation of NDCs, monitoring and assessment are critical for examining the effectiveness of adaptation measures as well as for achieving the necessary balance with mitigation activities. Communities can identify, select and monitor a set of indicators that are specific to the risks or vulnerability of their community forestry. To assess the effectiveness of adaptation measures, the global goal on adaptation (under Article 7) of the Paris Agreement identifies three major criteria: enhancing adaptive capacity, strengthening resilience and reducing vulnerability. Under these criteria, communities can establish a monitoring process by listing key impacts on forests and the community and determine relevant indicators for each impact. Communities can identify and select adaptation measures to address identified impacts and then evaluate the effectiveness of implemented adaption measures on these criteria.

\subsubsection{Assessment of quality of governance}

Ensuring good governance is critical for the effective implementation of projects, programmes and actions related to NDCs commitments. The realization of outcomes related to SFM, mitigation and adaptation largely depends on the quality of governance. Governance is multifaceted and comprises of coordination, clear roles and responsibilities, participation, information availability, inclusiveness, transparency and accountability, customs, the rule of law and decision making, mechanisms for fair distribution of incentives (cost, penalty, sanctions and benefits) between and among different jurisdictional levels. Governance is relevant to the NDCs as these cover the decisions, actors, processes, arrangements and policy tools needed to design and to implement climate action. Governance involves local, national and global actors from a wide range of sectors and relates to the institutional, policy and legal dimensions that will influence the successful implementation of climate action.

Since it is often difficult to quantify governance, a common standard for measuring the quality of governance is important at the community level. Expressing the quality of governance at the community forestry level recognizes the joint efforts by stakeholders to improve SFM practices, including effective climate action. Community forestry can also establish and apply a hierarchical approach based on PC\&I in a participatory manner to assess the quality of governance. Participants at the capacity assessment workshops concluded that the use of a standard approach is feasible and useful in trials of the PC\&I framework to access the quality of governance using principles of meaningful participation (as a governance structure) and productive 
deliberation (as a process) (Lopez-Casero et al., 2016). Again, capacity building, with the involvement of government and experts, is a key to design a local standard and ensure the effectiveness and usefulness of the governance assessment process.

It is evident that assessing SFM, mitigation, adaptation and quality of governance will involve overlaps. Given the increasing number of processes and limited resources, capacity building is particularly important to streamline all assessments and avoid redundancies. To this end, CFUGs can adopt a cross-referencing process to identify common indicators or verifiers that will fulfil more than one criterion and integrate them into a single process to assess multiple outcomes. The exercise will streamline all monitoring activities so that communities can use a single MRV using the PC\&I approach to assess the outcomes and performances.

\subsection{Integrated planning and implementation}

An IP\&I is indispensable to incorporate additional actions related to SFM, climate action and governance. IP\&I will help in assessing the resources needed to allocate division of roles and responsibilities and identify needed external support for finance, technology and capacity development.

Since a participatory approach is key for IP\&I, a mapping of all stakeholders involved is key for effective coordination. Communities should objectively conduct stakeholder mapping to allocate appropriate roles and responsibilities based on capacity, position and benefit/burdensharing, which is also useful in examining the level of coordination required both horizontally and vertically.

Implementation of SFM activities and climate action necessitate substantial human, financial, technical and institutional resources and capacity. Communities, therefore, need to plan their activities using available resources and capacity. The assessment helps to identify resources and capacity gaps and hence determine the feasibility of planned measures. Furthermore, it helps to build a strategy for seeking external support from government and non-government sources based on actual need. This strategy can significantly help communities to decide what kind of support to receive and what to decline.

IP\&I of SFM, mitigation, adaptation or governance is an adaptive process that involves continuous learning and improvement. An iterative approach like a PDCA (Plan, Do, Check and Act) cycle can be used. Although PDCA appears as an additional part of the planning process, the objective here is to prioritize action that communities can accomplish with the resources and capacity available to them. The focus is on gradual improvement in the performance of the PDCA cycle in the current year, although this is guided by long-term vision, goals and objectives. A stepwise approach provides valuable learning opportunities to communities, which is fundamental for adaptive planning.

\section{CONCLUSION}

Forests are strategic resources for tackling climate change problems and realization of the commitments in NDCs. Given that forests are a complex SES, targeting climate action without considering sustainability, community participation, rights, socio-economic and environmental concerns, will not be effective. There remain genuine capacity concerns at the community level regarding understanding roles and responsibilities, costbenefits, know-how and skills, and planning and implementing climate action. The action research identified the needs of capacity building to ensure that communities are engaged in the processes to integrate SFM, mitigation, adaptation and quality of governance for synergistic outcomes as well as to safeguard long-term interests. A comprehensive framework of capacity building at the community level, such as the one proposed in this paper, is necessary by integrating planning, implementation and assessment of key outcomes to translate NDCs commitment into actions, ensuring meaningful participation of CFUGs and facilitating enhanced communication to mainstream local action into national and international processes. 


\section{ACKNOWLEDGEMENT}

The authors would like to thank all stakeholders, experts and participants in the capacity building workshops for their valuable inputs and insights. We acknowledgement provincial governments of Nepal, in particular the Ministries of Industry, Tourism, Forests and Environment of Province 1 and Province 4 (Gandaki Province), Province 5 and Province 7, respectively, as well as the Federal Ministry of Forest and Environment of Nepal. The authors express special appreciation to the representatives of the Federation of Community Forestry Users Nepal and members of community forestry groups. We acknowledge the APN CAPaBLE programme for the financial support received under the project (CBA2018-08SY-Lopez-Casero).

\section{REFERENCES}

Aryal, K., Laudari, H.K., \& Ojha, H.R. (2020). To what extent is Nepal's community forestry contributing to the sustainable development goals? An institutional interaction perspective. International Journal of Sustainable Development \& World Ecology, (1), 27-27. doi:10.1080/13504509.2019.1627681

Austin, K.G., Baker, J.S., Sohngen, B.L., Wade, C.M., Daigneault, A., Ohrel, S.B., ... Bean, A. (2020). The economic costs of planting, preserving, and managing the world's forests to mitigate climate change. Nature Communications, (1), 11-11. doi:10.1038/s41467-02019578-z

Bastakoti, R.R., \& Davidsen, C. (2016). Nepal's REDD+ readiness preparation and multi-stakeholder consultation challenges. Journal of Forest and Livelihood, 13(1). doi:10.3126/jfl.v13i1.15364

Cadman, T., Maraseni, T., Ma, H.O., \& Lopez-Casero, F. (2017). Five years of REDD+ governance: The use of market mechanisms as a response to anthropogenic climate change. Forest Policy and Economics, 79, 8-16. doi:10.1016/j.forpol.2016.03.008

CBD. (2010). Aichi Target 17. Nagoya; United Nations.

Dhungana, S., Poudel, M., \& Bhandari (2018). REDD+ in Nepal: Experiences from the REDD readiness phase. REDD Implementation Centre, Ministry of Forests and Environment.

Edwards, K., Scheyvens, H., Stephenson, J., \& Fujisaki, T. (2014). Community based forest biomass monitoring: Training of trainers manual. Hayama, Japan.

FAO. (2016). Forty years of community-based forestry: A review of its extent and effectiveness. Retrieved from https://www.fao.org/publications/card/en/c/ b7c18106-c19d-412f-bd77-a35a2aeeoob5/

FAO. (2020a). Global forest resources assessment 2020. Retrieved from https://doi.org/10.4060/ca9825en

FAO. (2020b). Sustainable forest management. Retrieved from http://www.fao.org/forestry/sfm/85084/en/

FCPF. (2020). What is REDD+? Retrieved from https:// www.forestcarbonpartnership.org/what-redd

Feurer, M., Gritten, D., \& Than, M. (2018). Community forestry for livelihoods: Benefiting from Myanmar's mangroves. Forests, 9, 150-150. doi:10.3390/f9030150

Girardin, C., Jenkins, S., Seddon, N., Allen, M., Lewis, S., \& Wheeler, C. (2021). Nature-based solutions can help cool the planet - if we act now. Nature. doi:10.1038/d41586-021-01241-2

GoI. (2016). First Nationally Determined Contributions. Republic of Indonesia.

GoN/MoPE. (2016). Nationally Determined Contributions, Nepal. Government of Nepal.

IPCC. (2019). Climate Change and Land: an IPCC special report on climate change, desertification, land degradation, sustainable land management, food security, and greenhouse gas fluxes in terrestrial ecosystems.

ITTO. (2015). Voluntary guidelines for the sustainable management of natural tropical forests. Retrieved from https://www.itto.int/direct/topics/topics_pdf_ download/topics_id=4330\&no=0\&disp=inline

ITTO. (2016). Criteria and indicators for the sustainable management of tropical forests. Retrieved from https://www.itto.int/sustainable_forest_ management/criteria_indicators/

IUCN, \& ForestAction. (2020). Increasing ambition and action on NDCs through FLR. Retrieved from https://infoflr.org/what-flr/increasing-ambitionand-action-ndcs-through-flr

Lopez-Casero, F., Cadman, T., \& Maraseni, T. (2016). Quality-of-governance standards for forest management and emissions reduction. Developing community forestry and REDD+ governance through a multi-stage, multi-level and multi-stakeholder approach. Retrieved from https://www.iges.or.jp/en/pub/quality-governancestandards-forest-management/en

Lopez-Casero, F., Shivakoti, B.R., Maraseni, T., Pokharel, K., \& APN. (2021). Strengthening intersectoral coordination and governance for the effective implementation of Nepal's NDCs based on a voluntary national quality-of-governance standard for forest sector activities and programmes. Kobe, Japan: Asia-Pacific Network for Global Change Research. Retrieved 
from https://www.apn-gcr.org/publication/ strengthening-inter-sectoral-coordination-andgovernance-for-the-effective-implementation-ofnepals-ndcs-based-on-a-voluntary-nationalquality-of-governance-standard-for-forestsector-activit/

Maraseni, T.N., Poudyal, B.H., Rana, E., Khanal, S.C., Ghimire, P.L., \& Subedi, B.P. (2020). Mapping national REDD+ initiatives in the Asia-Pacific region. Journal of Environmental Management, (pp. 269-269). doi:10.1016/j.jenvman.2020.110763

Martn-Garca, J., \& Diez, J.J. (2012). Sustainable forest management: An introduction and overview. Sustainable Forest Management - Current Research. doi:10.5772/45839

MOFE (2018). Nepal National REDD+ Strategy. Ministry of Forest and Environment. Kathmandu, Nepal: Ministry of Forest and Environment.

MOFE. (2019). National Forest Policy 2019. Kathmandu. Nepal: Ministry of Forest and Environment.
RECOFTC. (2013). Community forestry in Asia and the Pacific: Pathway to inclusive development. Bangkok, Thailand.

UN. (2014). New York Declaration on Forests. New York.

UN. (2015). Transforming our world: the 2030 Agenda for Sustainable Development. Retrieved from https: //sdgs.un.org/2030agenda

UN. (2017). United Nations Strategic Plan for Forests 2017-2030. Retrieved from https://www.un.org/ esa/forests/wp-content/uploads/2017/09/UNSPFBriefing_Note.pdf

UNEP. (2018). The emissions gap report. Retrieved from https://www.unep.org/resources/emissions-gapreport-2018

UNFCCC. (2014). Handbook on measurement, reporting and verification for developing country parties. Retrieved from https://unfccc.int/files/national_ reports/annex_i_natcom_/application/pdf/nonannex_i_mrv_handbook.pdf

UNFCCC. (2015). The Paris Agreement. Retrieved from https://unfccc.int/process-and-meetings/theparis-agreement/the-paris-agreement 